\title{
Complementary somatic mutations of KCNJ5, ATP1A1, and ATP2B3 in sporadic aldosterone producing adrenal adenomas
}

\section{Dear Editor}

Primary aldosteronism (PA) is the most common form of secondary hypertension, accounting for $8-13 \%$ among hypertension patients (Mulatero et al. 2013). It is characterized by constitutive production of aldosterone by the adrenal cortex. Among the subtypes of PA, aldosteroneproducing adenomas (APAs), also known as Conn tumors, are characterized by tumors in the adrenal cortex and account for $30-40 \%$ of the cases. The two most important physiological stimuli of aldosterone secretion are angiotensin II and serum potassium. Decrease in blood volume activates the renin-angiotensin system, in which angiotensin II signals via the angiotensin receptor. The $\mathrm{K}^{+}$ concentration across the membrane sets the resting membrane potential. Hyperkalemia causes depolarization of the membrane and generates an action potential to open a voltage-gated $\mathrm{Ca}^{2+}$ channel. In both cases, enhanced intracellular $\mathrm{Ca}^{2+}$ provides the normal signal for aldosterone production. In APAs, autonomous production of aldosterone is found independently of angiotensin II.

Recently, next generation sequencing has revealed novel genes frequently mutated in APAs: KCNJ5, ATP1A1, and ATP2B3 (Choi et al. 2011, Taguchi et al. 2012, Beuschlein et al. 2013, Mulatero et al. 2013). In these pivotal studies, mutations in KCNJ5, encoding an inwardly rectifying $\mathrm{K}^{+}$channel, were identified in about $30-45 \%$ of patients. The $\mathrm{K}^{+}$channel encoded by KCNJ5 exists both as homo-tetramer and as a hetero-tetramer with another potassium channel encoded by KCNJ3. The latter has been found more active than homo-tetramers (Choi et al. 2011). More recently, mutations in ATP1A1 (encode a $\mathrm{Na}^{+} / \mathrm{K}^{+}$pump ATPase $\alpha$ subunit) and ATP2B3 (plasma membrane $\mathrm{Ca}^{2+}$ ATPase) have been reported, each of which appears in about 6 and $2 \%$ of the tumors respectively (Beuschlein et al. 2013). In this study, we investigated KCNJ5, KCNJ3, ATP1A1, and ATP2B3 for mutations in a series of 35 consecutive patients with sporadic APAs from Norway, Sweden, and Germany (protocols and primers available on request).

We found frequent somatic mutations in KCNJ5, $A T P 1 A 1$, and ATP2B3. No mutations were identified in $K C N J 3$ which is in agreement with previous reports (Choi et al. 2011, Taguchi et al. 2012, Beuschlein et al. 2013).

Regarding KCNJ5 (NM_000890.3), 11 (31\%) missense mutations were identified. Seven mutations were at c. $451 \mathrm{G}>\mathrm{A}$ (p.Gly151Arg), one at c. $451 \mathrm{G}>\mathrm{C}$ (p.Gly151Arg), and three at c.503T $>$ G (p.Leu168Arg) (Fig. 1a, b and c respectively). The overall mutation frequency was in agreement with previous reports (Choi et al. 2011, Taguchi et al. 2012). Notably, the somatic mutations G151R and L168R are situated on the highly conserved glycine-tyrosine-glycine (GYG) motif of the selective filter and the second transmembrane (TM) domain of KCNJ5 respectively (Heginbotham et al. 1992). The GYG motif in the extracellular loop of all four subunits of the KCNJ5 channel forms the narrowest part of the pore. Both mutations abolish the highly conserved region of the GYG motif. In in vitro studies, it appears that all mutations potentially lead to a loss of ion selectivity of the channel protein (Choi et al. 2011). Furthermore, reduction of inward $\mathrm{K}^{+}$current results in enhanced depolarization of the adrenal cell membranes, which leads to activation of voltage-gated $\mathrm{Ca}^{2+}$ channels. An increase in intracellular $\mathrm{Ca}^{2+}$ is associated with higher aldosterone production.

Regarding ATP1A1, two missense variants (6\%) were identified at c.311T $>$ G (p.Leu104Arg) (Fig. 1d). Concerning $A T P 2 B 3$, three inframe deletions (9\%) were found, two of c.1272_1277delGCTGGT (p.Leu425-Val426del) and one of c.1281_1286delGGCTGT (p.Arg428-Val429del) (Fig. 1e and f). The overall mutation frequencies were slightly higher than in one previous report (Beuschlein et al. 2013), which may be due to small sample size. Of note,we identified the novel mutation c.1281_1286delGGCTGT in ATP2B3.

Published by Bioscientifica Ltd. 
(a) WT $\quad$ KCNJ5 $r \begin{gathered}\mathrm{G} 151 \mathrm{R} \\ \text { (c.451G>A) }\end{gathered}$ C CA T TGGG ICCAT TRGG

(b) KCNJ5 WT C CATTGGG (c)

G151R (c. $451 \mathrm{G}>\mathrm{C}$ )

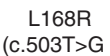

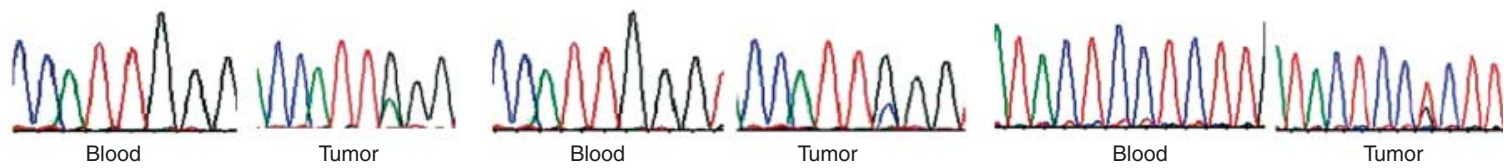

(d)

ATP1A1

WT

TTACTGTGG TTACTGTGG

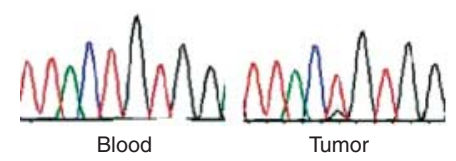

(e) $\begin{array}{cc}\text { WT } & \text { p.Leu425-Val426 } \\ \text { (c.1272_1277delGCTGGT) }\end{array}$ CGTGGCTG (f)

ATP2B3

p.Arg428-Val429 (c.1281_1286delGGCTGT)

CGTGGCTGTC CGT G 5 C T GW C C CA A A
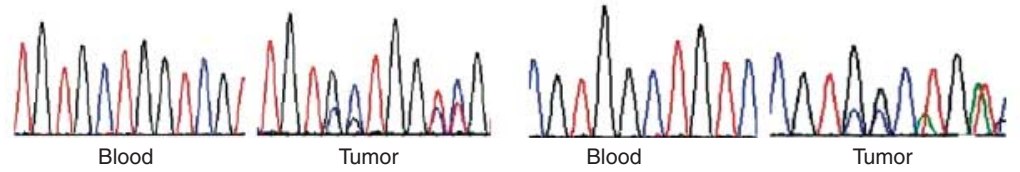

(g) ATP2B3

ATP2B1

ATP2B2

ATP2B 4

ATP2A1

ATP2A2

Blood

Tumor

Blood

Tumor

ATP2A3

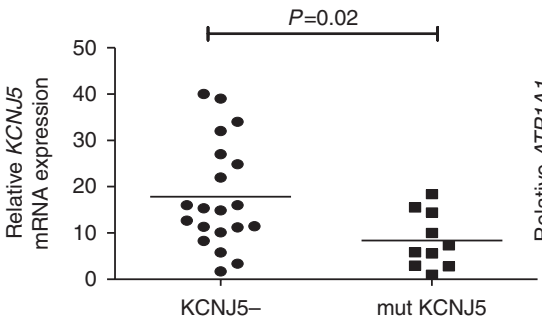

(k)

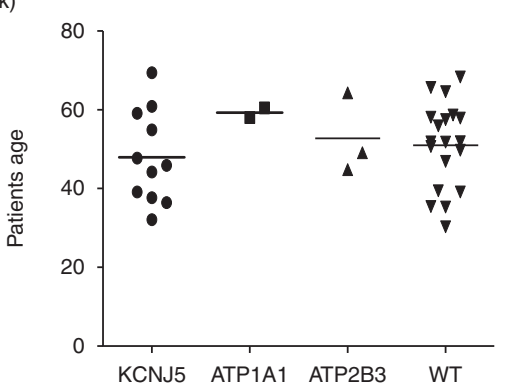

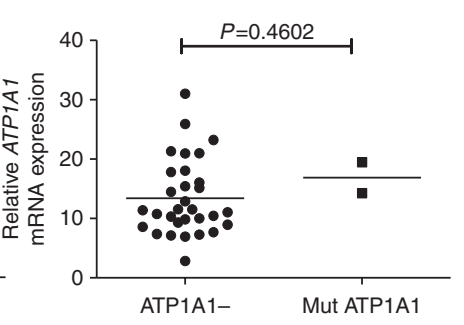

(I)

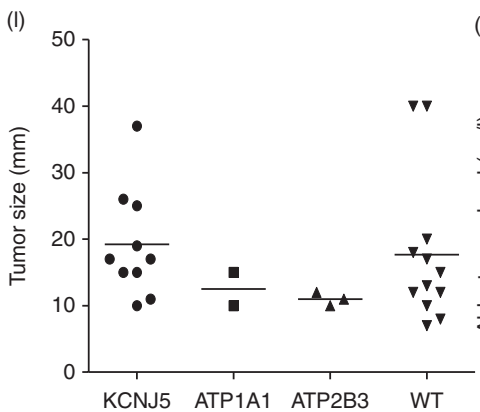

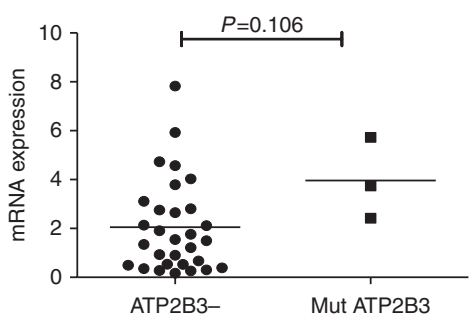

(m)

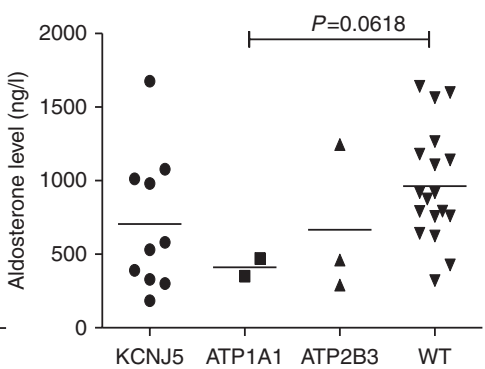

(n)

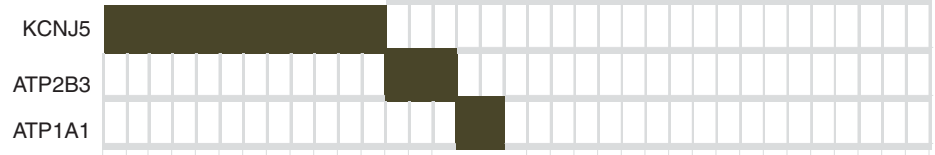


Table 1 Clinical characteristic of 16 APA patients with different mutations in KCNJ5, ATP1A1, and ATP2B3

\begin{tabular}{lcc} 
& & \\
Sample & Age (years) \\
\cline { 1 - 1 } L1 & 39.1 \\
L15 & & 49.1 \\
L37 & 58.0 \\
L58 & 45.9 \\
L70 & 32.1 \\
B1 & 64.3 \\
B2 & 37.7 \\
B9 & 36.4 \\
B17 & 47.7 \\
G1 & 54.9 \\
G2 & 60.5 \\
G3 & 69.4 \\
G4 & 60.9 \\
G6 & 59.1 \\
L131 & 44.2 \\
L141 & 44.8 \\
\hline
\end{tabular}

\begin{tabular}{|c|c|}
\hline Sex & $\begin{array}{c}\text { Preoperative } \\
\text { aldosterone (ng/l) }\end{array}$ \\
\hline$M$ & 580 \\
\hline $\mathrm{F}$ & 290 \\
\hline $\mathrm{M}$ & 470 \\
\hline $\mathrm{F}$ & 530 \\
\hline $\mathrm{F}$ & 980 \\
\hline $\mathrm{M}$ & 1246 \\
\hline $\mathrm{F}$ & 1675 \\
\hline $\mathrm{F}$ & 1013 \\
\hline$M$ & 1078 \\
\hline $\mathrm{M}$ & 300 \\
\hline$M$ & 350 \\
\hline $\mathrm{F}$ & 329 \\
\hline$M$ & 184 \\
\hline $\mathrm{F}$ & NA \\
\hline$F$ & 390 \\
\hline$M$ & 460 \\
\hline
\end{tabular}

\begin{tabular}{c}
\hline Size $(\mathrm{mm})$ \\
\hline 7 \\
10 \\
10 \\
10 \\
25 \\
11 \\
17 \\
37 \\
17 \\
26 \\
15 \\
19 \\
15 \\
11 \\
15 \\
12
\end{tabular}

\begin{tabular}{l} 
Gene \\
\hline KCNJ5 \\
ATP2B3 \\
ATP1A1 \\
KCNJ5 \\
KCNJ5 \\
ATP2B3 \\
KCNJ5 \\
KCNJ5 \\
KCNJ5 \\
KCNJ5 \\
ATP1A1 \\
KCNJ5 \\
KCNJ5 \\
KCNJ5 \\
KCNJ5 \\
ATP2B3
\end{tabular}

\begin{tabular}{l} 
cDNA bp \\
\hline c. $451 \mathrm{G}>\mathrm{A}$ \\
c.1281_1286delGGCTGT \\
c. $311 \mathrm{~T}>\mathrm{G}$ \\
c. $451 \mathrm{G}>\mathrm{C}$ \\
c. $503 \mathrm{~T}>\mathrm{G}$ \\
c. $1272 \_1277$ delGCTGGT \\
c. $503 \mathrm{~T}>\mathrm{G}$ \\
c. $451 \mathrm{G}>\mathrm{A}$ \\
c. $451 \mathrm{G}>\mathrm{A}$ \\
c. $451 \mathrm{G}>\mathrm{A}$ \\
c.311T $>\mathrm{G}$ \\
c. $503 \mathrm{~T}>\mathrm{G}$ \\
c. $451 \mathrm{G}>\mathrm{A}$ \\
c. $451 \mathrm{G}>\mathrm{A}$ \\
c. $451 \mathrm{G}>\mathrm{A}$ \\
c. $1272 \_1277$ delGCTGGT
\end{tabular}

M, male; F, female; NA, not available.

The protein encoded by both genes ATP1A1 and ATP2B3 exchanges $\mathrm{K}^{+}$and $\mathrm{Ca}^{2+}$ ions, respectively, by hydrolysis of one ATP (Kaplan 2002, Di Leva et al. 2008). On the crystal structure of ATP1A1, the mutant L104R is located in the TM $\alpha$ helix M1, which has been suggested to interact and cooperate in $\mathrm{K}^{+}$ion binding and gating by interaction with Glu334 (Morth et al. 2007). It has been found that angiotensin II inhibits the $\mathrm{Na}^{+} / \mathrm{K}^{+}$pump activity for aldosterone production in glomerulosa cells (Hajnoczky et al. 1992). As $\mathrm{Ca}^{2+}$ ion pumps are highly conserved, we used sarcoplasmic reticulum type $\mathrm{Ca}^{2+}$ ATPase (SERCA) to project the mutations. The deletions 425Ala_426Val and 428Ala_429Val corresponds to 303Ala_304Val and 306Ala_307Ile (Fig. 1g). The PEGLP motif after Ile307 is a key motif for ion gating and is highly conserved among the p-type pumps (Di Leva et al. 2008). Mutations potentially lead to the distortion of this $\mathrm{Ca}^{2+}$ binding region. Notably, in both ATPase genes, the mutation abolishes Glu334 and Glu309 in ATP1A1 and ATP2B3 that are crucially important for ion gating. Functional ex vivo studies of the role of the loss of function mutations in the ATPase genes (Beuschlein et al. 2013) showed substantially higher levels of depolarization in the mutant cells.

In this study, the expression of KCNJ5 at the mRNA level was found to be significantly lower in mutated samples $(P=0.02)$ (Fig. 1h). This finding is in disagreement with previous results (Taguchi et al. 2012, Boulkroun et al. 2013). The reason for this discrepancy might be the rather small sample size. In contrast to KCNJ5, the mRNA expression levels of $A T P 1 A 1$ and $A T P 2 B 3$ were not affected by mutational status (Fig. 1i and $\mathrm{j}$ respectively). This is in agreement with previous results (Beuschlein et al. 2013).

Clinical characteristics of the patients are shown in Table 1 . In contrast to patients with KCNJ5 mutations, ATPase mutated APAs were predominantly found in males (Table 1). There was no statistically significant difference concerning the age of patients having APAs with different mutations (Fig. 1k).

Although the tumor size of APAs with somatic KCNJ5 mutations was almost twice the size of APAs with either

\section{Figure 1}

Sequences of blood DNA showing no mutation (WT) and mutated tumor DNA showing the following somatic missense mutations: c.451G $>A(a)$, c.451G $>$ C (b) and c.503T $>$ G (c). Normal blood and mutated tumor DNA sequences regarding ATP1A1 (c.311T>G) (d), c.1272_1277delGCTGGT ATP2B3 (e), and c.1281_1286delGGCTGT (f), respectively). Alignment of plasma membrane $\mathrm{Ca}^{2+}$ ATPase pumps and sarcoplasmic reticulum type $\mathrm{Ca}^{2+}$ ATPases $(\mathrm{g})$. Colored region are conserved among them. The arrow indicates the deleted residues in our cases. The PEGLP motif is conserved among all p-type pump. It is a key factor for ion gating. mRNA expression of $K C N J 5$ in APAs with mutation (mut KCNJ5) and without $K C N J 5$ mutation $(\mathrm{KCN} 5-)(\mathrm{h})$. The mRNA levels of mutated $K C N J 5$ were significantly lower
$(P=0.02)$. Expression of ATP1A1 mRNA of APAs with (mut ATP1A1) and without mutation (ATP1A1 -) (i). Expression of ATP2B3 mRNA in APAs with (mut ATP2B3) and without mutation (ATP2B3-) (j). Age of patients with APAs with regard to the somatic mutation (KCNJ5, ATP1A1, and $A T P 2 B 3)(\mathrm{k})$. Diameter of APAs with regard to the somatic mutation (I). Comparison of aldosterone levels of the patients with APAs with regard to the somatic mutation (KCNJ5, ATP2B3, and ATP1A1) (m). Lines show the mean value of each group. Complementary mutations of $K C N J 5, A T P 2 B 3$, and ATP1A. Mutation frequencies of $31 \%$ for $K C N J 5,9 \%$ for $A T P 2 B 3$, and $6 \%$ for ATP1A1 were observed in our cohort $(n)$. http://erc.endocrinology-journals.org DOI: $10.1530 /$ ERC-13-0466
(C) 2014 Society for Endocrinology Printed in Great Britain
Published by Bioscientifica Ltd. 
somatic $A T P 1 A 1$ and $A T P 2 B 3$ mutations, this difference was not statistically significant (Fig. 11). No conclusions could be drawn from the preoperative aldosterone levels (Fig. 1m).

In conclusion, somatic mutations found in KCNJ5, $A T P 1 A 1$, and ATP2B3 appear to be the driving forces for a higher aldosterone production and proliferations of glomerulosa cells. All mutations found in this study were complementary to each other (Fig. 1n), indicating that multiple genes may contribute independently to the formation of APAs.

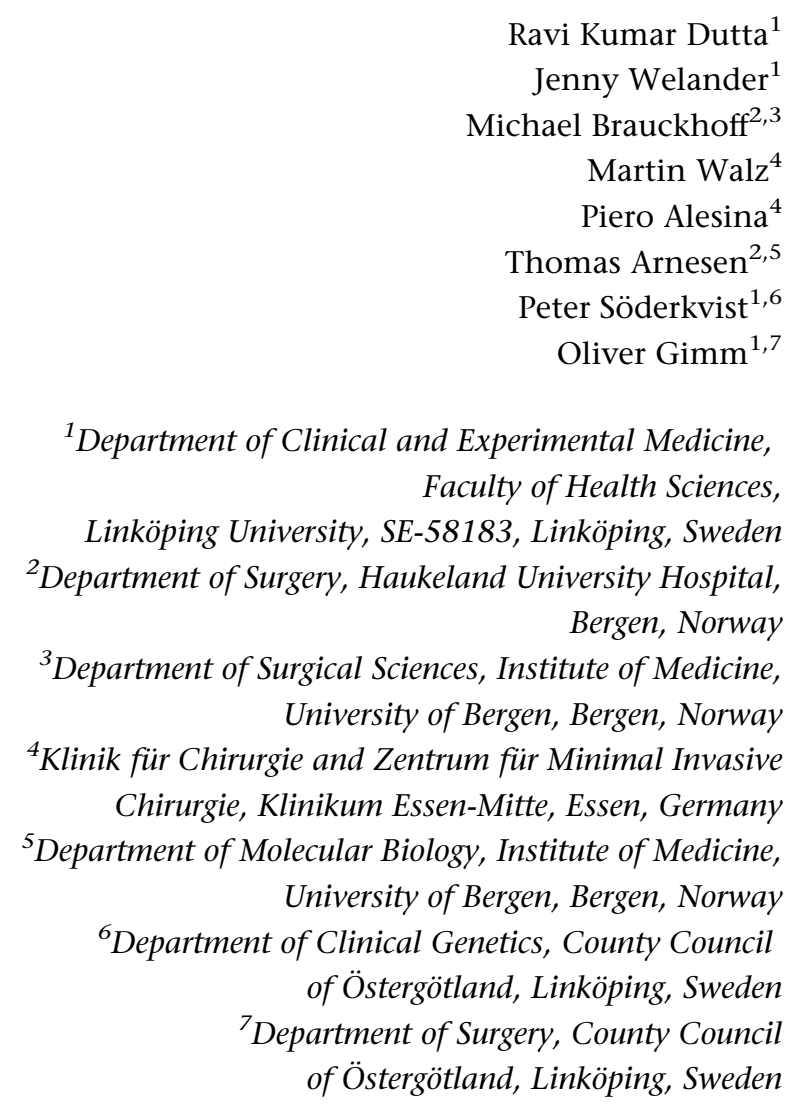

(Correspondence should be addressed to O Gimm); email: oliver.gimm@liu.se

\section{Declaration of interest}

The authors declare that there is no conflict of interest that could be perceived as prejudicing the impartiality of the research reported.

\section{Funding}

This work was supported by grants from Linköping University to both O Gimm and P Söderkvist.

Author contribution statement

P Söderkvist and O Gimm contributed equally to this work.

\section{Acknowledgements}

The authors thank Annette Molbaek and Åsa Schippert for technical assistance.

\section{References}

Beuschlein F, Boulkroun S, Osswald A, Wieland T, Nielsen HN, Lichtenauer UD, Penton D, Schack VR, Amar L, Fischer E et al. 2013 Somatic mutations in ATP1A1 and ATP2B3 lead to aldosterone-producing adenomas and secondary hypertension. Nature Genetics $\mathbf{4 5} 440-444,444 \mathrm{e} 441-442$. (doi:10.1038/ng.2550)

Boulkroun S, Golib Dzib JF, Samson-Couterie B, Rosa FL, Rickard AJ, Meatchi T, Amar L, Benecke A \& Zennaro MC 2013 KCNJ5 mutations in aldosterone producing adenoma and relationship with adrenal cortex remodeling. Molecular and Cellular Endocrinology 371 221-227. (doi:10. 1016/j.mce.2013.01.018)

Choi M, Scholl UI, Yue P, Bjorklund P, Zhao B, Nelson-Williams C, Ji W, Cho Y, Patel A, Men CJ et al. $2011 \mathrm{~K}^{+}$channel mutations in adrenal aldosterone-producing adenomas and hereditary hypertension. Science 331 768-772. (doi:10.1126/science.1198785)

Di Leva F, Domi T, Fedrizzi L, Lim D \& Carafoli E 2008 The plasma membrane $\mathrm{Ca}^{2+}$ ATPase of animal cells: structure, function and regulation. Archives of Biochemistry and Biophysics 476 65-74. (doi:10.1016/j.abb.2008.02.026)

Hajnoczky G, Csordas G, Hunyady L, Kalapos MP, Balla T, Enyedi P \& Spat A 1992 Angiotensin-II inhibits $\mathrm{Na}^{+} / \mathrm{K}^{+}$pump in rat adrenal glomerulosa cells: possible contribution to stimulation of aldosterone production. Endocrinology 130 1637-1644. (doi:10.1210/en.130.3.1637)

Heginbotham L, Abramson T \& MacKinnon R 1992 A functional connection between the pores of distantly related ion channels as revealed by mutant $\mathrm{K}^{+}$channels. Science 258 1152-1155. (doi:10.1126/science.1279807)

Kaplan JH 2002 Biochemistry of Na,K-ATPase. Annual Review of Biochemistry 71 511-535. (doi:10.1146/annurev.biochem.71.102201.141218)

Morth JP, Pedersen BP, Toustrup-Jensen MS, Sorensen TL, Petersen J, Andersen JP, Vilsen B \& Nissen P 2007 Crystal structure of the sodiumpotassium pump. Nature 450 1043-1049. (doi:10.1038/nature06419)

Mulatero P, Monticone S, Rainey WE, Veglio F \& Williams TA 2013 Role of KCNJ5 in familial and sporadic primary aldosteronism. Nature Reviews. Endocrinology 9 104-112. (doi:10.1038/nrendo.2012.230)

Taguchi R, Yamada M, Nakajima Y, Satoh T, Hashimoto K, Shibusawa N, Ozawa A, Okada S, Rokutanda N, Takata D et al. 2012 Expression and mutations of KCNJ5 mRNA in Japanese patients with aldosteroneproducing adenomas. Journal of Clinical Endocrinology and Metabolism 97 1311-1319. (doi:10.1210/jc.2011-2885)

Received in final form 25 October 2013

Accepted 30 October 2013

Made available online as an Accepted Preprint

30 October 2013 http://erc.endocrinology-journals.org DOI: 10.1530/ERC-13-0466
(C) 2014 Society for Endocrinology Printed in Great Britain
Published by Bioscientifica Ltd. 